\title{
Active Earth Pressure against Rigid Retaining Walls for Finite Soils in Sloping Condition considering Shear Stress and Soil Arching Effect
}

\author{
Weidong Hu, Kangxing Liu $(\mathbb{D}$, Xinnian Zhu, Xiaolong Tong, and Xiyu Zhou \\ Hunan Institute of Science and Technology, Yueyang 414000, China \\ Correspondence should be addressed to Kangxing Liu; 12003026@hnist.edu.cn
}

Received 5 July 2019; Accepted 6 January 2020; Published 24 February 2020

Academic Editor: Amir Si Larbi

Copyright (C) 2020 Weidong Hu et al. This is an open access article distributed under the Creative Commons Attribution License, which permits unrestricted use, distribution, and reproduction in any medium, provided the original work is properly cited.

\begin{abstract}
The horizontal differential layer element method was used to study the active earth pressure of the finite-width soil formed by the rigid retaining wall for the embankment or adjacent foundation pits. The cohesionless soil was taken as the research object, and the soil arch theory was introduced based on the translation mode of rigid retaining wall and the linear sliding fracture surface. The minor principal stress line was assumed as circular, considering the deflected principal stress as soil arching effect. The shear stress between level soil layers in the failure wedge was calculated, and the differential level layer method was modified. Then, the theoretical formula of the active earth pressure, the resultant earth pressure, and the point of application of resultant earth pressure were obtained using this revised method. The predictions by the proposed formula were compared with the existing methods combined with the cases. It is shown that the resultant finite pressure increases gradually and approaches to Coulomb active earth pressure values when the soil is infinite, with the increase of the ratios of the backfill width to height. Moreover, the horizontal pressure for limited soils is distributed nonlinearly along the wall height. Considering the shear stress between level soil layers and the soil arching effect, the position of application point of the resultant active earth pressure by the proposed formulation is higher than that of Coulomb's solution. The wall is rougher, and the resultant pressure will be smaller. The application point distance from the bottom of the wall will increase. Finally, an experiment was conducted to verify the distribution of the active earth pressure for finite soil against rigid retaining wall, and the research results agree well with those of the experimented observations.
\end{abstract}

\section{Introduction}

In recent years, a large number of high-fill embankment retaining walls or adjacent foundation pit retaining walls have appeared in roads and municipal engineering and urban underground projects, forming a sloping finite-width soil mass. When the soil of this kind of retaining wall works, the sliding rupture surface fails to fully develop to the horizontal plane and the boundary condition and failure mode of the retaining wall are not in accordance with the theoretical calculation conditions of the semi-infinite soil classical earth pressure. Therefore, the calculation of the active earth pressure of the finite soil mass in the embankment retaining wall requires a novel method or research based on the mechanism of finite width soil failure.
With the prolonged efforts of scholars, the theoretical research on the active earth pressure of finite width soil rigid retaining walls has achieved substantial achievements [1-8]. However, most research objects focus on the narrow-width soil in adjacent building (basement) wall or bedrock, that is, the boundary side of the limited soil is fixed, and the other side of the retaining wall is slightly deformed. The study of active earth pressure on the sloping finite soil behind the retaining wall for the embankment is relatively rare, and there are few related reports and literatures. Liu [9] numerically simulated the finite soil under sloping conditions, but the boundary conditions were similar to those of adjacent buildings. Xie et al. [10] used the upper bound theory to derive the active earth pressure formula of the limited soil of the retaining wall for the embankment, which assumes 
that the retaining wall is vertical and smooth without considering the friction between the back and soil layer of the retaining wall; Fang et al. [11] derived the active earth pressure resultant force formula of limited soil under sloping conditions using the limit equilibrium method. But, it did not study the distribution of finite earth pressure.

Existing indoor model tests and field test studies have shown that the earth pressure behind the retaining wall is a nonlinear distribution [12-14]. It is important to explore the earth pressure calculation model reflecting the nonlinear distribution law in this research field. To examine the active earth pressure distribution well, the microstratification analysis method was proposed to calculate the earth pressure coefficient according to the horizontal microstratification equilibrium condition and obtained the high nonlinear distribution of earth pressure along the rigid retaining wall in the translational mode. Some scholars have improved their methods and achieved abundant results, which promoted the development of theoretical research on earth pressure on retaining walls to some extent [15-18].

However, there are still two deficiencies in studying the pressure distribution law of soil (either a semi-infinite soil or a finite-width soil) using the microstratification unit static equilibrium condition. On one hand, existing research methods usually do not consider the shear stress among the horizontal microlayers of the sliding soil wedge, which also lack the rationality of the processing method. Generally, the frictional force induced by the rough back of the retaining wall and the filling causes the principal stressdeflection in the soil. Furthermore, the shear stress exists in the horizontal direction, forming a soil arching effect, so that the active earth pressure of the retaining wall in the translational mode is significantly nonlinear. Therefore, the horizontal shear stress is inevitable to consider [19-21]. On the other hand, some research methods do not consider the soil arching effect caused by the friction between the retaining wall and the filling, as well as the filling and sliding surface. The main stress deflection causes a large change in the actual stress state, and it cannot be used only by the force and moment balance conditions of the microstratified unit to derive the earth pressure calculation formula, because in fact, the different shear stress distribution patterns on the horizontal plane will directly affect the moment balance conditions [22-24]. Therefore, it is still necessary to unify the static balance conditions, the shear stress on the microlayered unit, and the stress deflection in the back of the retaining wall caused by the soil arching effect.

Li et al. [25] studied the lateral pressure of restricted cohesionless material through numerical calculation and theoretical analysis. The transition of the lateral pressure can be divided into two stages, and the stress is redistributed due to the superposition of arching effect for model with smaller width. Liu [6] studied the active earth pressures of the limited cohesionless fills for rigid retaining walls in mountainous regions and adjacent existing basement foundation pit. The reasonable distribution of earth pressure is obtained with considering the shear stress between differential layers.
Based on above evidence, the engineering characteristics of the finite-width soil of rigid retaining wall under sloping conditions were initially studied, and the cohesionless filler was taken as the research object to solve the limit rupture angle using the overall static equilibrium condition based on the translational failure mode of the retaining wall. Then, considering the soil arching effect caused by the friction between the retaining wall and the filling as well as the filling on sliding surface, the soil arching theory of the finite soil in the deformation zone is introduced, and the circular arc trajectories of minor principal stresses after the stress deflection were used to obtain the lateral active earth pressure coefficient and the average shear stress coefficient through Mohr's stress circle; afterwards, the horizontal microlayering analysis method is used to calculate the horizontal shear stress between the horizontal microlayers and the horizontal microstratification analysis method is corrected, thereby an active earth pressure calculation model was established.

\section{Retaining Wall Analysis Model and Slip Surface}

As shown in Figure 1, the height of the rigid retaining wall is $H$, the back of the wall is vertical, and the slope behind the wall is filled with cohesionless soil. The bottom angle of the slope is $\beta$, the finite width of top surface of the wall is $l$, the surface of the fill is horizontal, the friction angle in the soil is $\varphi$, the gravity is $\gamma$, and the external friction angle between the back wall of the retaining wall and the fill is $\delta$ :

$$
\left.\begin{array}{l}
\overline{c d}=l+\frac{H}{\tan \beta} \\
\overline{d f}=\left(l+\frac{H}{\tan \beta}\right) \frac{\sin \beta}{\sin (\alpha+\beta)} \\
\overline{e d}=\left(l+\frac{H}{\tan \beta}\right) \frac{\sin \beta \sin \alpha}{\sin (\alpha+\beta)} \\
\overline{e f}=\left(l+\frac{H}{\tan \beta}\right) \frac{\sin \beta \cos \alpha}{\sin (\alpha+\beta)} \\
h=H-\left(l+\frac{H}{\tan \beta}\right) \frac{\sin \beta \sin \alpha}{\sin (\alpha+\beta)}
\end{array}\right\} .
$$

When the retaining wall for the embankment reaches the active limit state in the translational displacement mode, the slip surface is not fully developed to the top surface of the fill but stopped on the slope surface due to the limited width of the soil, and it is assumed that the plane slip surface passes through the bottom of the wall and forms an angle $\alpha$ with the horizontal plane according to the Coulomb earth pressure theory. The geometric parameters of the model shown in the figure satisfy the relation (1). The limit rupture angle $\alpha$ can be obtained by applying the method of the active earth pressure resultant force extreme value. 


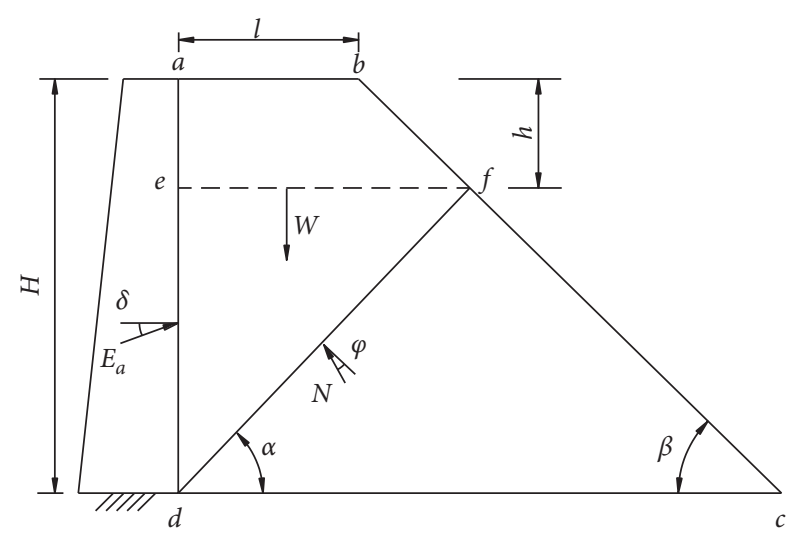

FIGURE 1: Slip surface through the slope surface.

As shown in Figure 1, the abfd sliding wedge is taken as the research object. According to the Coulomb theory method, the finite active earth pressure formula can be obtained. Firstly, the equilibrium equation using the vertical direction and the horizontal static force is established as follows:

$$
\begin{array}{r}
W-E_{a} \sin \delta-N \cos (\alpha-\varphi)=0, \\
E_{a} \cos \delta-N \sin (\alpha-\varphi)=0 .
\end{array}
$$

where $E_{a}$ is the active earth pressure resultant force, the direction is opposite to the normal line of the back of the wall, acting below the normal line; $N$ is the reaction force on the sliding surface, whose direction forms an angle $\varphi$ with the normal of the slip surface and acts below the normal; and $W$ is the self-weight of the abfd sliding wedge. Formulas (2) and (3) are synthesized and obtained as follows:

$$
E_{a}=\frac{W}{\sin \delta+\cos \delta \cot (\alpha-\varphi)} .
$$

When the soil reaches the active limit state, the corresponding most dangerous slip surface fracture angle value is solved $[6,11]$. The limit fracture angle is a function of $\varphi, \gamma, l$ $H$, and $\delta$, and its explicit expression is difficult to obtain in this problem. The actual solution can be realized by the iterative search method, and the limit rupture angle can calculate the following substituted formula (4), thereby obtaining the active earth pressure resultant force $E_{a}$ based on the generalized Coulomb theory.

\section{Active Earth Pressure Intensity Solution}

As above, the limit rupture angle can be obtained by using the overall static equilibrium condition. Based on this, the horizontal microhierarchical element method is used to establish active earth pressure differential equation under the force balance condition and then carry out the distribution of active earth pressure. According to the relative movement trend of the differential horizontal layer elements of the soil wedge behind the wall, it can be divided into three areas and the soil can be divided into upper and lower areas by the ef boundary, namely, the I and III zones, and the thin layer elements of transitional zone II is on the ef boundary. As shown in Figure 2, based on the relative movement trend and static equilibrium condition of the horizontal layer elements in each zone, the shear stress action direction among the layer elements of each partition is further analyzed by establishing equilibrium equations.

3.1. Zone I. The sliding fracture surface develops from the bottom of the wall to the slope because of the small displacement of the retaining wall. The movement trend of the upper soil units is affected by the sliding of the lower soil units. As shown in Figure 3, the force analysis is performed for the horizontal differential layer elements of zone I and the static balance condition of the horizontal direction can be obtained:

$$
\sigma_{h 1} d z-\tau_{1} d z \cot \beta-d \tau_{1}(l+z \cot \beta)=0 .
$$

where the second-order differentials have been omitted (the second-order differentials are also omitted in the later calculation process, not listed again), $\sigma_{h 1}$ is the horizontal active earth pressure at the depth $z$, and $\tau_{1}$ is the horizontal shear stress of the horizontal unit surface, assuming its average distribution, which can be expressed as

$$
\tau_{1}=\sigma_{v 1} k_{1} \text {. }
$$

where $k_{1}$ is the average shear stress coefficient of zone I element, which is the ratio of the average shear stress $\tau_{1}$ to the average vertical stress $\sigma_{v 1}$, which is more complex and affected by the sliding tendency of the horizontal element, and $k_{1}$ is generally a function of wall height, and should be less than $\tan \varphi$. In order to simplify the calculation, the linear variation of $k_{1}$ with the calculated depth is considered in the height range of zone $\mathrm{I}$, and the expression is as follows:

$$
k_{1}=\frac{z k_{h}}{h}
$$

where $k_{h}$ is the average shear stress coefficient at the height $h$, that is, the bottom surface of the zone I. According to the vertical static balance condition of the horizontal unit, it can be calculated as follows:

$$
\tau_{w 1} d z+\sigma_{v 1} d z \cot \beta+d \sigma_{v 1}(l+z \cot \beta)-d w_{1}=0
$$

where $\tau_{w 1}$ is the friction shear stress on the contact surface between the retaining wall and the soil, and its size can be expressed as

$$
\tau_{w 1}=\sigma_{h 1} \tan \delta
$$

where $d_{w 1}$ is the self-weight of the horizontal differential unit of zone I and its size can be expressed as

$$
d w_{1}=\gamma(l+z \cot \beta) d z \text {. }
$$

Formulas (5) and (8) are synthesized as follows:

$$
\sigma_{h 1}=\frac{k_{1} \gamma(l+z \cot \beta)}{k_{1} \tan \delta+1} .
$$

Then, the lateral earth pressure intensity at the bottom of zone I can be obtained when $z=h$ as follows: 


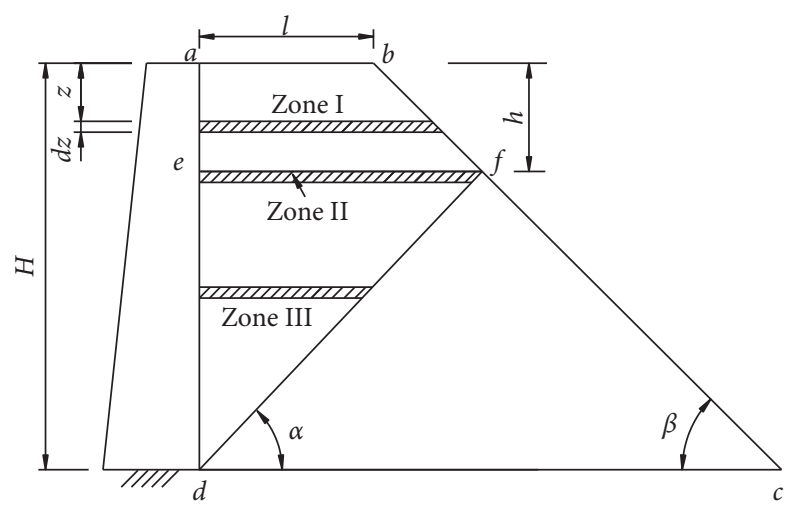

Figure 2: Calculation model of active earth pressure.

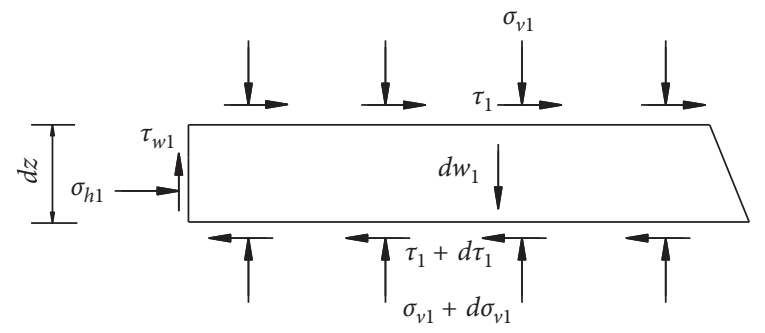

FIGURE 3: Forces acting on horizontal elements of zone I.

$$
\left.\sigma_{h 1}\right|_{z=h}=\frac{k_{h} \gamma(l+h \cot \beta)}{k_{h} \tan \delta+1}
$$

Substituting equation (11) into equation (5), there is

$$
\frac{\mathrm{d} \sigma_{v 1}}{\mathrm{~d} z}+\frac{\cot \beta \sigma_{v 1}}{l+z \cot \beta}-\frac{\gamma}{k_{1} \tan \delta+1}=0
$$

When $z=0$ and $\sigma_{v 1}=0$ are the boundary conditions of the zone I region, and the first-order linear differential equation of equation (13) can be obtained:

$$
\sigma_{v 1}=\frac{\gamma\left(l z+(1 / 2) \cot \beta z^{2}\right)}{\left(k_{1} \tan \delta+1\right)(l+z \cot \beta)} .
$$

When $z=h$ and $\sigma_{v 1}=D_{1}$ can be used as the boundary condition for the equivalent loading of the top surface of the II region separator:

$$
D_{1}=\frac{\gamma\left(l h+(1 / 2) \cot \beta h^{2}\right)}{\left(k_{h} \tan \delta+1\right)(l+h \cot \beta)} .
$$

3.2. Zone II. Zone II is a thin transition layer with a height of $\Delta z$. The vertical average compressive stress $\sigma_{v 2}=D_{1}$ is applied to the top surface of the $z=h$ thin layer, and the vertical average compressive stress of the thin layer is $\sigma_{v 2}+\Delta \sigma_{v 2}$, as shown in Figure 4. It is shown that the thin layer of zone II is the research object and is solved according to its equilibrium condition [26]. When $\Delta z \longrightarrow 0$, it can be obtained:

$$
\Delta \sigma_{v 2}=\frac{-2 k_{h} \sigma_{v 2}}{k_{h}+\tan (\alpha-\varphi)} \text {. }
$$

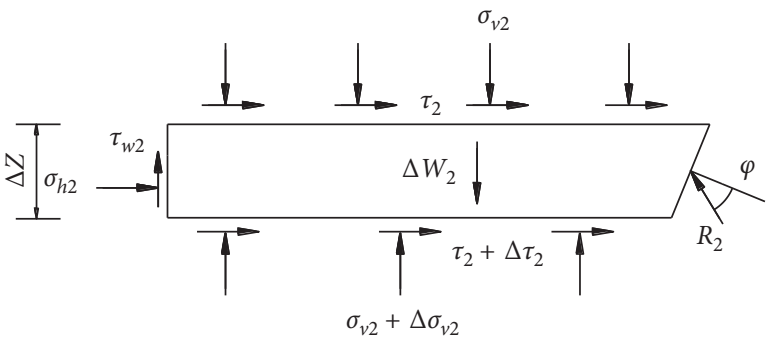

Figure 4: Forces acting on horizontal elements of zone II.

The vertical average compressive stress at the bottom of the $z=h$ thin layer element is

$$
\sigma_{v 2}+\Delta \sigma_{v 2}=\frac{-k_{h}+\tan (\alpha-\varphi)}{k_{h}+\tan (\alpha-\varphi)} \sigma_{v 2} .
$$

Therefore, the bottom surface average compressive stress $\sigma_{v 2}+\Delta \sigma_{v 2}=D_{2}$ can be used as the equivalent loading boundary condition of the top surface of the III region separator:

$$
D_{2}=\frac{-k_{h}+\tan (\alpha-\varphi)}{k_{h}+\tan (\alpha-\varphi)} D_{1} \text {. }
$$

3.3. Zone III. The stress and boundary conditions of the soil in Zone III are very different from those of the soil above. The vertical and lateral deformation of the soil is deflected by the friction between the wall and the friction of the soil in the sliding surface. The principal stress direction is deflected, and the shear stress is generated in the horizontal direction, forming a soil arching effect and resulting in a nonlinear distribution of earth pressure. Regarding the minor principal stress trajectory, previous evidence has demonstrated that the curve is an arch-shaped curve, which can usually be represented by a circular arc, a catenary, or a parabola $[17,19,27]$. This paper uses a circular shape trajectory commonly used by many scholars to establish a calculation model as shown in Figure 5. After the stress deflection of the $E F$ thin layer unit, an arc shape curve having a radius $R$ is formed through the $E$ point and the center of the circle is the $O$ point.

The stress at the $Q$ point on the arc arch line is expressed as

$$
\left.\begin{array}{l}
\sigma_{v Q}=\frac{\sigma_{1}}{1+\sin \varphi}(1-\sin \varphi \cos 2 \theta) \\
\sigma_{h Q}=\frac{\sigma_{1}}{1+\sin \varphi}(1+\sin \varphi \cos 2 \theta) \\
\tau_{Q}=\frac{\sigma_{1} \sin \varphi}{1+\sin \varphi} \sin 2 \theta
\end{array}\right\} .
$$

where $\theta$ is the angle between the large principal stress at $Q$ point and the horizontal plane; the angle between points $E$ and $F$ is expressed as 


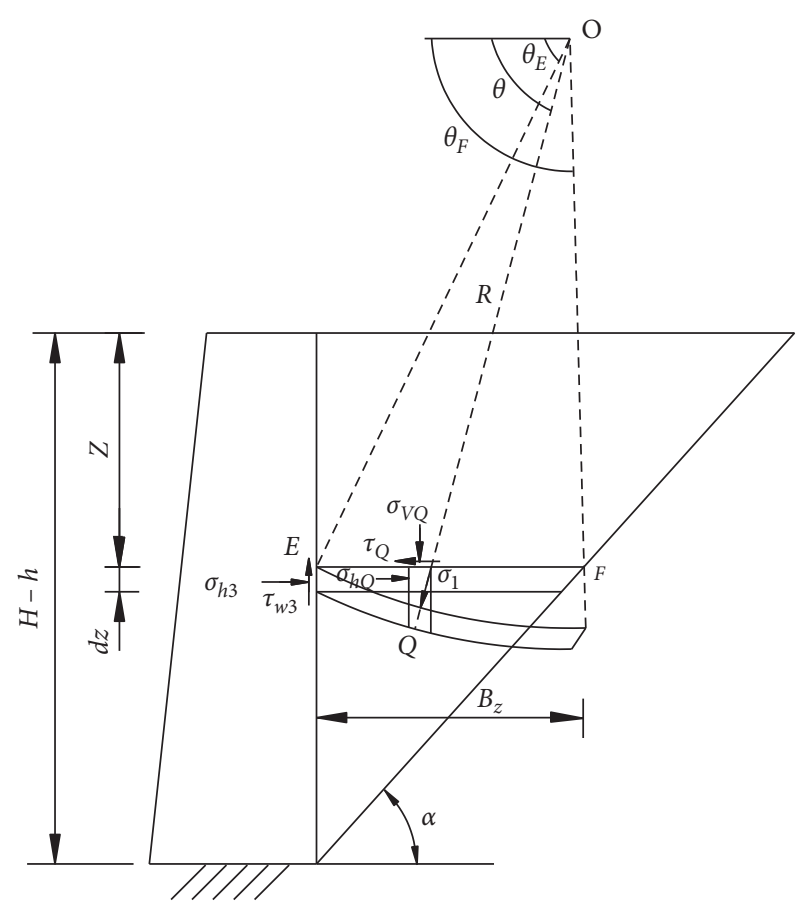

FIgURE 5: Trajectory of minor principal stress of zone III.

$$
\left.\begin{array}{l}
\theta_{E}=\frac{1}{2}\left[\pi-\arcsin \left(\frac{\sin \delta}{\sin \varphi}\right)+\delta\right] \\
\theta_{F}=\frac{\pi}{4}-\frac{\varphi}{2}+\alpha
\end{array}\right\} .
$$

The radius of the minor principal stress arch curve is expressed as

$$
R=\frac{B_{z}}{\cos \theta_{E}-\cos \theta_{F}} .
$$

where $B_{\mathrm{z}}$ is the horizontal length of the horizontal thin layer. The lateral active earth pressure coefficient $[6,19,27]$ can be defined as

$$
K_{a w n}=\frac{\sigma_{h 3}}{\overline{\sigma_{v}}}
$$

where $\sigma_{h 3}$ is the horizontal lateral pressure at the depth $z$ of the retaining wall; $\overline{\sigma_{v}}$ is the average vertical pressure at the same depth level. In the second formula of the general formula (19) and the first formula of formula (20), the horizontal lateral stress $\sigma_{h 3}$ on the $E$ point can be obtained. Using the integral of the first formula in equation (19), the vertical average stress $\overline{\sigma_{v}}$ on the plane of the zone III with the depth of $z$ can be obtained, followed by substituting $\sigma_{h 3}$ and $\overline{\sigma_{v}}$ into equation (22) as follows:

$$
K_{a w n}=\frac{\cos ^{2} \theta_{E}+K_{a R} \sin ^{2} \theta_{E}}{1+\left(\left(\cos ^{2} \theta_{E}+\cos \theta_{E} \cos \theta_{F}+\cos ^{2} \theta_{F}\right)\left(K_{a R}-1\right)\right) / 3} .
$$

where $K_{a R}$ is the Rankine active earth pressure coefficient, and its expression is as follows:

$$
K_{a R}=\tan ^{2}\left(\frac{\pi}{4}-\frac{\varphi}{2}\right) .
$$

The ratio of the average shear stress to the average vertical stress on the thin layer of the element is used to represent the average shear stress coefficient $k$ of the element as follows:

$$
k=\frac{2 \sin \varphi\left(\sin ^{3} \theta_{F}-\sin ^{3} \theta_{E}\right)}{3(1+\sin \varphi)\left(\cos \theta_{E}-\cos \theta_{F}\right)-2 \sin \varphi\left(\cos ^{3} \theta_{E}-\cos ^{3} \theta_{F}\right)} .
$$

From equation (22), the lateral earth pressure at the top of zone III can be obtained when $z=h$ as follows:

$$
\left.\sigma_{h 3}\right|_{z=h}=K_{a w n}\left(\sigma_{v 2}+\Delta \sigma_{v 2}\right) \text {. }
$$

Considering the continuity of the horizontal lateral stress of the retaining wall, when $z=h$, the $\sigma_{h 1}$ at the bottom of zone I is equal to the horizontal stress of the $\sigma_{h 3}$ at the top of zone III. Using this stress continuity condition, it can be obtained, by substituting equations (15) and (17) into equation (26), as follows:

$$
\begin{aligned}
\frac{k_{h} \gamma(l+h \cot \beta)}{k_{h} \tan \delta+1}= & K_{a w n} \cdot \frac{-k_{h}+\tan (\alpha-\varphi)}{k_{h}+\tan (\alpha-\varphi)} \\
& \cdot \frac{\gamma\left(l h+(1 / 2) \cot \beta h^{2}\right)}{\left(k_{h} \tan \delta+1\right)(l+h \cot \beta)} .
\end{aligned}
$$
follows:

Through simplifying formula (27), it is obtained as

$$
k_{h}=\frac{K_{a w n}\left(l h+(1 / 2) \cot \beta h^{2}\right)}{(l+h \cot \beta)^{2}}\left[\frac{-k_{h}+\tan (\alpha-\varphi)}{k_{h}+\tan (\alpha-\varphi)}\right] .
$$

Then, the force analysis is carried out with the horizontal differential layer units of zone III as the research object, and the differential layers slide under the action of gravity, as shown in Figure 6.

The geometric relationship of the horizontal elements in zone III is as follows:

$$
\left.\begin{array}{l}
\overline{g j}=(H-z) \cot \theta \\
\overline{m n}=(H-z-d z) \cot \theta \\
\overline{n j}=\frac{d z}{\sin \theta}
\end{array}\right\} .
$$

The equation is established according to the static equilibrium condition acting in the horizontal direction on the horizontal unit, and it can be obtained when the secondorder differential component is omitted as follows:

$$
\sigma_{h 3} d z-\tau_{3} d z \cot \alpha+d \tau_{3}(H-z) \cot \alpha-\frac{R_{3} \sin (\alpha-\varphi) d z}{\sin \alpha}=0 .
$$

where $\sigma_{h 3}$ is the horizontal active earth pressure; $R_{3}$ is the reaction force on the sliding slope; the direction is $\varphi$ angle to the normal of the slope, acting below the normal; $\sigma_{v 3}$ is the vertical normal stress distributed on the surface of the 


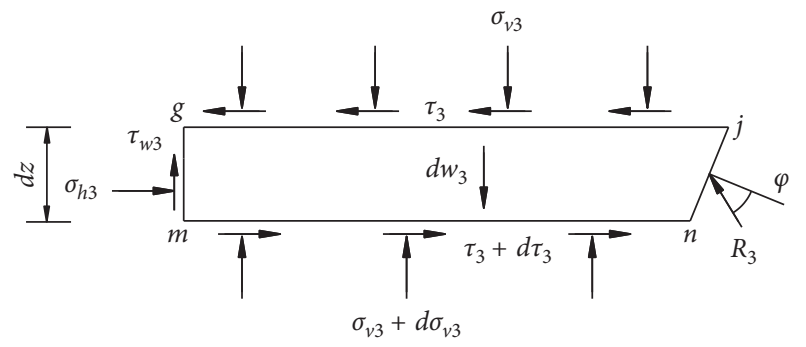

Figure 6: Forces acting on horizontal elements of zone III.

horizontal element; $\tau_{3}$ is the horizontal shear stress on the surface of the horizontal element, assuming it is an average distribution; the average shear stress coefficient in the height range of the zone III is $k$ along the wall height, and the size of $\tau_{3}$ can be expressed as

$$
\tau_{3}=\sigma_{v 3} k
$$

According to the vertical static balance condition of the horizontal unit, it can be obtained as follows:

$$
\tau_{w 3} d z-\sigma_{v 3} \cot \alpha d z+d \sigma_{v 3}(H-z) \cot \alpha+\frac{R_{3} \cos (\alpha-\varphi) d z}{\sin \alpha}-d w_{3}=0
$$

where $\tau_{w 3}$ is the friction shear stress on the contact surface between the retaining wall and the soil, and it is given as follows:

$$
\tau_{w 3}=\sigma_{h 3} \tan \delta
$$

where $d_{w 3}$ is the self-weight of the horizontal unit of zone III, and its size is expressed as

$$
d w_{3}=\gamma(H-z) \cot \alpha d z .
$$

Combining formulas (30) and (32), a first-order differential equation can be established as follows:

$$
\frac{\mathrm{d} \sigma_{v 3}}{\mathrm{~d} z}+\frac{B \sigma_{v 3}}{A(H-z)}-\frac{C}{A} \gamma=0
$$

In this formula,

$$
\left.\begin{array}{c}
A=\cot \alpha[k \cos (\alpha-\varphi)+\sin (\alpha-\varphi)] \\
B=\left(K_{a w n}-k \cot \alpha\right) \cos (\alpha-\varphi) \\
+\left(K_{a w n} \tan \delta-\cot \alpha\right) \sin (\alpha-\varphi) \\
C=\cot \alpha \sin (\alpha-\varphi)
\end{array}\right\} .
$$

After solving the differential equation of formula (35), it can be obtained through the boundary condition formula (18) as follows:

$$
\sigma_{v 3}=\frac{-C \gamma(H-z)}{A-B}+\left[D_{2}+\frac{C \gamma(H-h)}{A-B}\right]\left(\frac{H-z}{H-h}\right)^{B / A} .
$$

Substituting the above formula (37) into formula (22), it can be obtained the active earth pressure intensity of zone III as follows:

$$
\begin{aligned}
\sigma_{h 3}= & K_{a w n} \sigma_{v 3}=-K_{a w n} \frac{C \gamma(H-z)}{A-B} \\
& +K_{a w n}\left[D_{2}+\frac{C \gamma(H-h)}{A-B}\right]\left(\frac{H-z}{H-h}\right)^{B / A} .
\end{aligned}
$$

\section{Active Earth Pressure Combined Force and Action Point Position}

Integrating $\sigma_{h 1}$ and $\sigma_{h 3}$ high sublevels along the wall, the horizontal component $E_{a x}$ of the soil pressure resultant force of the entire retaining wall can be obtained:

$$
\begin{aligned}
E_{a x}= & \int_{0}^{h} \sigma_{h 1} \mathrm{~d} z+\int_{h}^{H} \sigma_{h 3} \mathrm{~d} z=\gamma \cdot\left[G_{2}\left(h+G_{1} \ln \frac{G_{1}}{G_{1}+h}\right)\right. \\
& \left.+G_{3}\left(\frac{1}{2} h^{2}-h G_{1}+G_{1}^{2} \ln \frac{G_{1}+h}{G_{1}}\right)\right] \\
& +\frac{K_{a w n}}{2(A+B)}\left[C \gamma(H-h)^{2}+2 * D_{2} * A(H-h)\right] .
\end{aligned}
$$

In this formula,

$$
\left.\begin{array}{l}
G_{1}=\frac{h}{k_{h} \tan \delta} \\
G_{2}=\frac{l}{\tan \delta} \\
G_{3}=\frac{\cot \beta}{\tan \delta}
\end{array}\right\} .
$$

The active earth pressure resultant expression is as follows:

$$
\begin{aligned}
E_{a}= & \frac{E_{a x}}{\cos \delta}=\frac{\gamma}{\cos \delta} \cdot\left[G_{2}\left(h+G_{1} \ln \frac{G_{1}}{G_{1}+h}\right)\right. \\
& \left.+G_{3}\left(\frac{1}{2} h^{2}-h G_{1}+G_{1}^{2} \ln \frac{G_{1}+h}{G_{1}}\right)\right] \\
& +\frac{K_{a w n}}{2(A+B) \cos \delta}\left[C \gamma(H-h)^{2}+2 D_{2} A(H-h)\right] .
\end{aligned}
$$

Horizontal active earth pressure resultant force point distance from wall bottom $y$ is as follows: 


$$
\begin{aligned}
y= & \frac{\int_{0}^{h} \sigma_{h 1}(H-z) \mathrm{d} z+\int_{h}^{H} \sigma_{h 3}(H-z) \mathrm{d} z}{E_{a x}} \\
= & \frac{1}{E_{a x}} \cdot\left[\gamma \left[H G_{2}\left(h+G_{1} \ln \frac{G_{1}}{G_{1}+h}\right)\right.\right. \\
& +G_{4}\left(\frac{1}{2} h^{2}-h G_{1}+G_{1}^{2} \ln \frac{G_{1}+h}{G_{1}}\right) \\
& \left.-G_{3}\left(\frac{1}{3} h^{3}-\frac{1}{2} h^{2} G_{1}+h G_{1}^{2}+G_{1}^{3} \ln \frac{G_{1}}{G_{1}+h}\right)\right] \\
& \left.+\frac{K_{a w n}}{3(2 A+B)}\left[C \gamma(H-h)^{3}+3 D_{2} A(H-h)^{2}\right]\right] .
\end{aligned}
$$

In this formula,

$$
G_{4}=\frac{H \cot \beta-l}{\tan \delta} .
$$

\section{Example Analysis}

5.1. Comparative Analysis. In order to verify the rationality of the shear stress and soil arch layered element method, the active earth pressure is calculated by an example in the literature [11], and the results are compared with those based on Coulomb's Theory of earth Pressure. The slope layer behind the retaining wall $(H=10$ and $H=15)$ is cohesionless soil layer, which is vertical. The external friction angle between the wall and soil is $\delta=2 / 3 \varphi$. The results are shown in Table 1.

The calculated limit fracture angle decreases with the increase of the ratio of width to height $(l / H)$, which is in line with the results of Coulomb Theory [11]. Alongside that, the resultant earth pressure $E_{a}$ calculated by the generalized Coulomb method in this paper (equation (4)) is consistent with the calculation results in [11], and the result of $E_{a}$ calculated by differential layer method proposed in this paper (equation (41)) is almost close to the results in Coulomb Theory [11], reflecting the common regularity that with the increase of the ratio of $l / H$; the resultant earth pressure $E_{a}$ of finite soil increases and approaches to Coulomb's pressure value of infinite soil. This is because the three analysis methods are based on the static equilibrium condition, assuming that slipping surface forms are the same, where the horizontal shear stress actually has little effect on the resultant force value of the soil. So the earth pressure resultant force is calculated by the improved differential layer method, and its regularity stands in line with other two methods. However, as shown in Figures 7 and 8, this paper improves the differential layer method to consider the shear stress and soil arching effect, and the distribution law of horizontal component of earth pressure along the height range of the wall can be obtained. In these figures, The distribution curve of the horizontal component of active earth pressure is nonlinear drum shaped, which is similar to
TABLE 1: Calculated values of limit rupture angle and active earth pressure under different $l / H$.

\begin{tabular}{lccccccccccc}
\hline \multicolumn{1}{c}{$H=10 \mathrm{~m}$} & \multicolumn{4}{c}{$H=15 \mathrm{~m}$} \\
$l / H$ & \multicolumn{1}{c}{$\alpha\left({ }^{\circ}\right)$} & \multicolumn{3}{c}{$E_{a}(\mathrm{kN} / \mathrm{m})$} & \multicolumn{4}{c}{$\alpha\left(^{\circ}\right)$} & \multicolumn{3}{c}{$E_{a}(\mathrm{kN} / \mathrm{m})$} \\
& (1) & (2) & (1) & (2) & (3) & (1) & (2) & (1) & (2) & (3) \\
\hline 0.1 & 62.7 & 62.7 & 314 & 314.6 & 293.8 & 62.7 & 62.7 & 706 & 705.7 & 661.0 \\
0.2 & 61.4 & 61.4 & 352 & 351.7 & 332.5 & 61.4 & 61.4 & 791 & 791.4 & 748.1 \\
0.3 & 59.7 & 59.7 & 381 & 381.2 & 365.3 & 59.7 & 59.7 & 858 & 857.8 & 821.8 \\
0.4 & 57.8 & 57.8 & 403 & 403.5 & 392.1 & 57.8 & 57.8 & 908 & 907.8 & 882.2 \\
0.5 & 55.8 & 55.8 & 420 & 419.7 & 413.2 & 55.8 & 55.8 & 944 & 944.4 & 929.7 \\
0.6 & 53.8 & 53.8 & 431 & 431.0 & 428.6 & 53.8 & 53.8 & 970 & 969.9 & 964.5 \\
0.7 & 51.8 & 51.8 & 438 & 438.3 & 438.7 & 51.8 & 51.8 & 986 & 986.1 & 987.2 \\
0.8 & 49.9 & 49.9 & 442 & 442.1 & 443.5 & 49.9 & 49.9 & 995 & 994.8 & 997.9 \\
0.9 & 48.1 & 48.1 & 443 & 443.2 & 443.1 & 48.1 & 48.1 & 997 & 997.3 & 996.9 \\
\hline (1) Reference [11], (2) Coulomb's method in this paper, (3) Differential layer
\end{tabular}

the distribution curve of earth pressure that has been studied in the translation mode of rigid retaining wall $[16,20,21]$.

5.2. Position and Quality of the Acting Point of the Active Earth Pressure Force. The position of the resultant force of the earth pressure is an important parameter for checking the stability of the anti-overturning of the rigid retaining wall. According to Coulomb's theory of the semi-infinite soil, the ground pressure resultant force point is located in the lower third of the wall without overloading. In Figure 9, it shows the calculation of the literature [11] using the method of this paper. The height of the wall is $H=10 \mathrm{~m}$ and $H=15 \mathrm{~m}$. When the external friction angle is $\delta=\varphi, \delta=2 / 3 \varphi$, and $\delta=1 /$ $3 \varphi$, it can be seen from the figure that considering the horizontal shear stress between soil layers and soil arching, the position of the finite earth pressure resultant force point is slightly higher than the Coulomb theoretical value when $\delta>0$; with the increase of the external friction angle $\delta$ of retaining wall and the soil, the position of the resultant force point increases. At the same time, it can be seen that as the aspect ratio $l / H$ increases, the position of the resultant force point increases and tends to a fixed point.

As shown in Figure 10, the wall friction height is $H=10 \mathrm{~m}$ and $H=15 \mathrm{~m}$ and the external friction angle between the retaining wall and the fill is taken as the resultant value of the earth pressure with $\delta=2 / 3 \varphi, \delta=1 / 3 \varphi$, and $\delta=0$, respectively. The coarser the soil surface, the larger the friction angle, the smaller the value of the active earth pressure combined force, and the soil pressure resultant value increases nonlinearly with the increase of the aspect ratio and tends to a stable value.

\section{Test Verification}

In view of the fact that there are few examples of active earth pressure calculation of the finite soil in the high-filled embankment retaining wall and in order to verify the correctness of the earth pressure distribution curve studied in this paper, the model test is conducted to compare the soil pressure distribution patterns. 


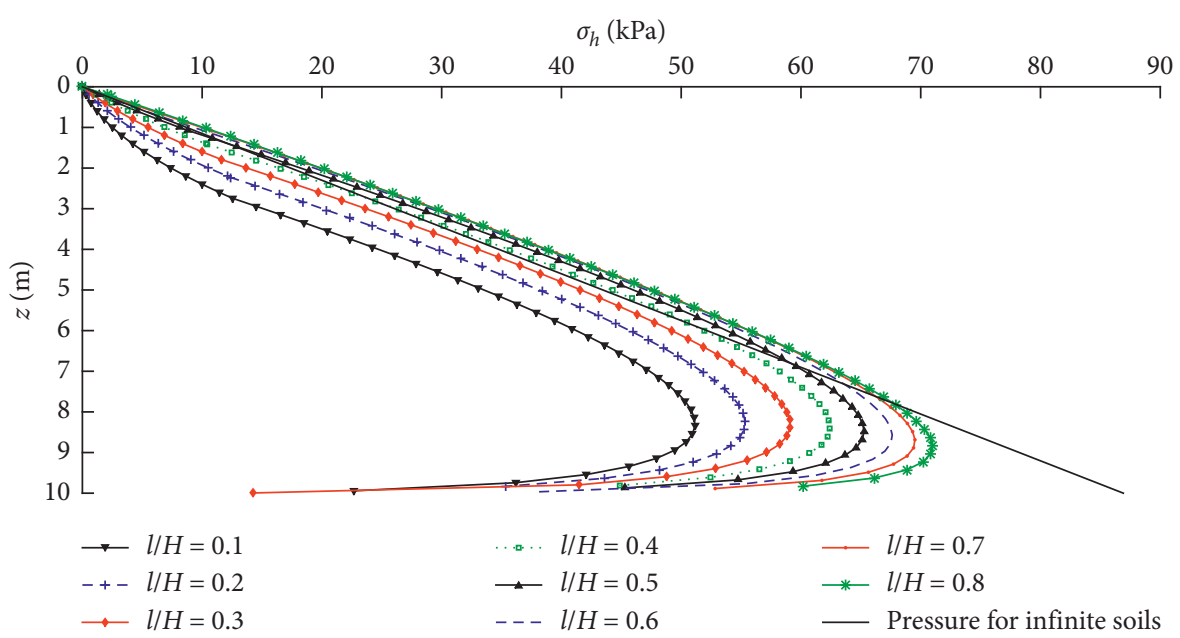

Figure 7: Distribution of active earth pressure under different $l / H$ values $(H=10 \mathrm{~m})$.

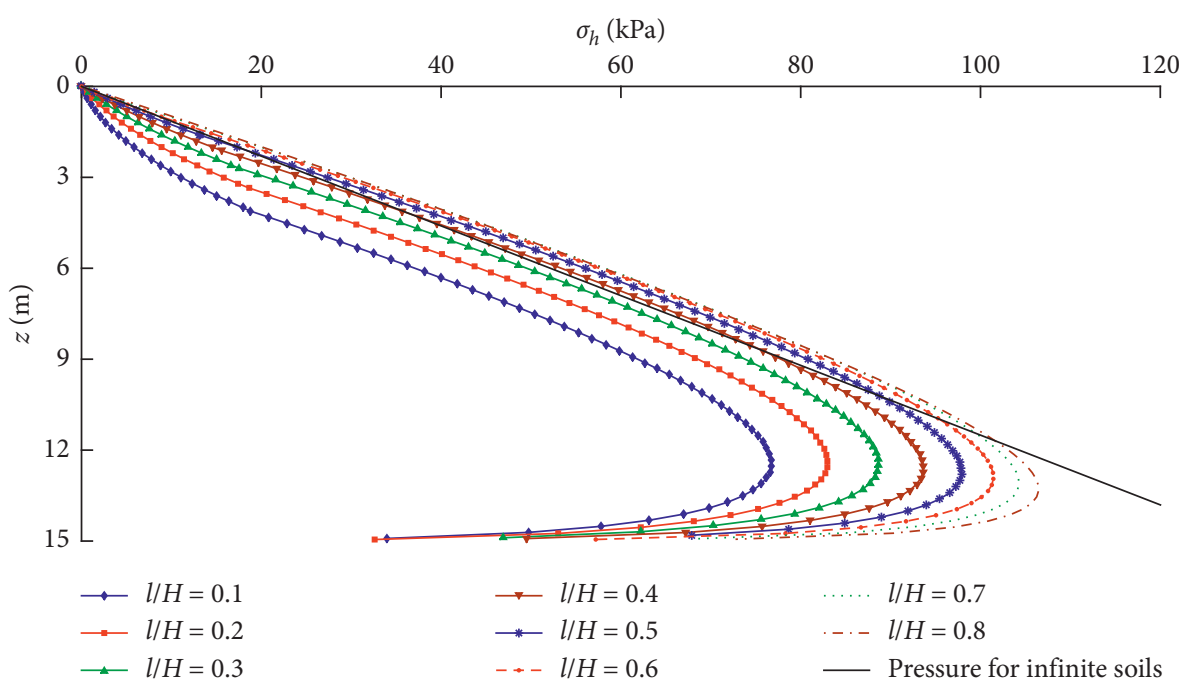

Figure 8: Distribution of active earth pressure under different $l / H$ values $(H=15 \mathrm{~m})$.

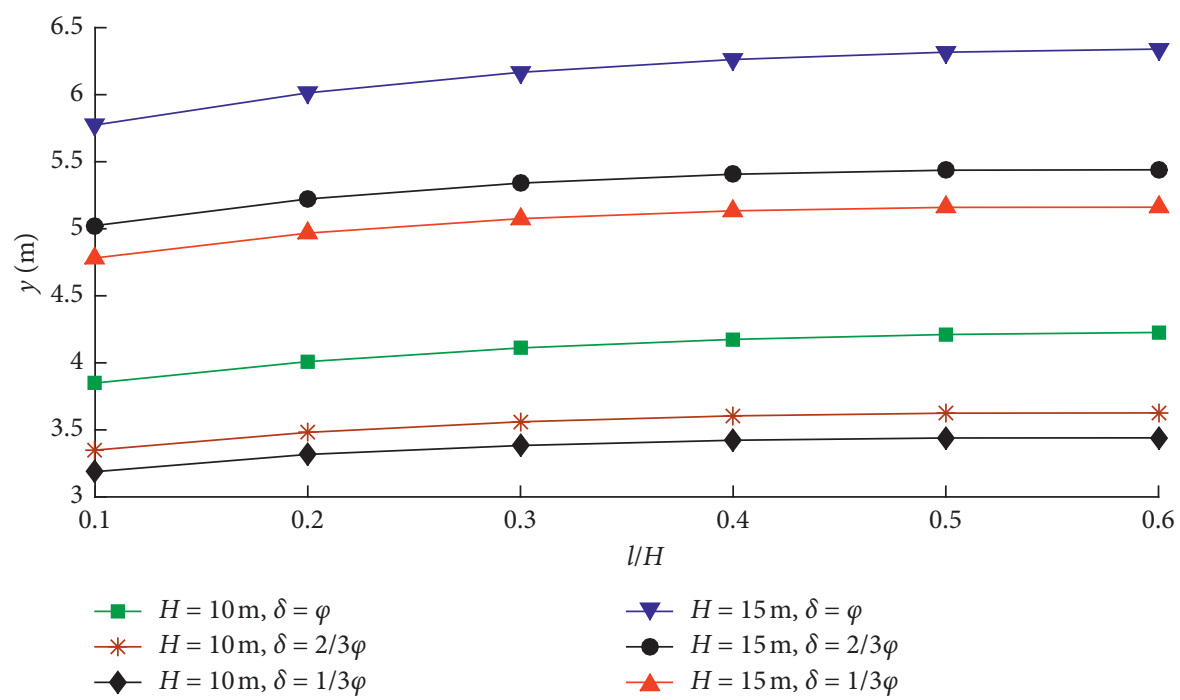

Figure 9: The height of action line of the resultant earth pressure. 


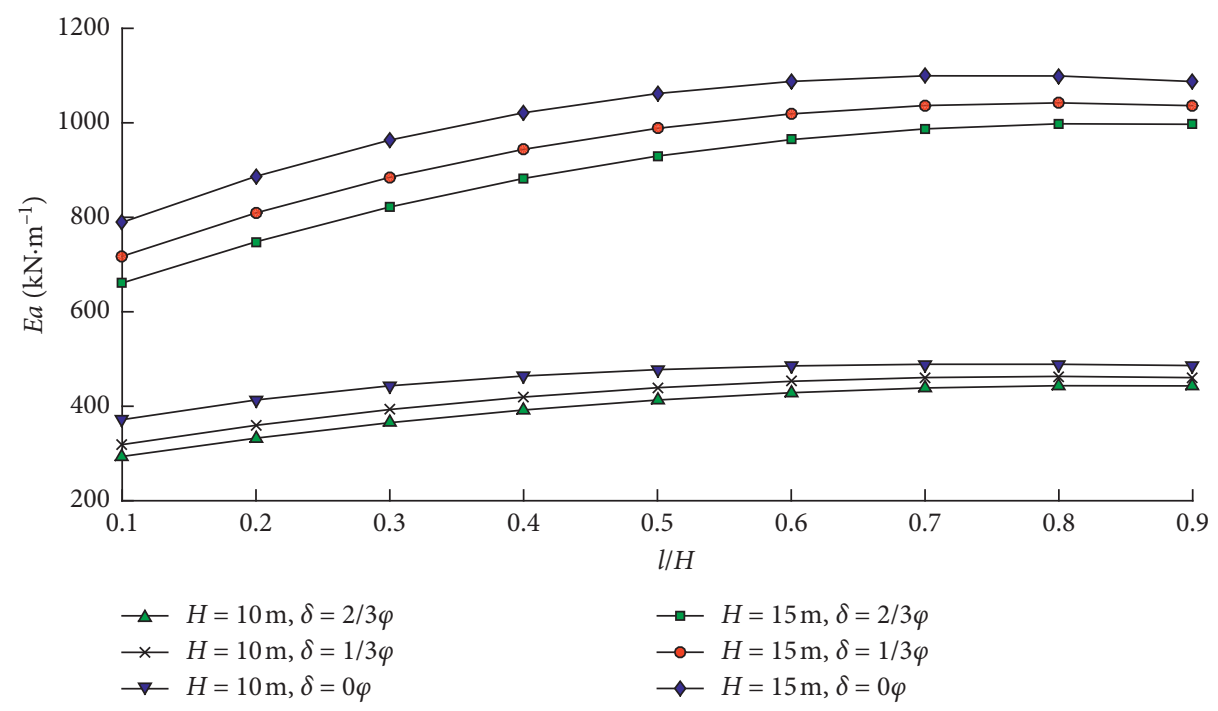

Figure 10: The resultant earth pressure under different $l / H$ and $\delta$ values.

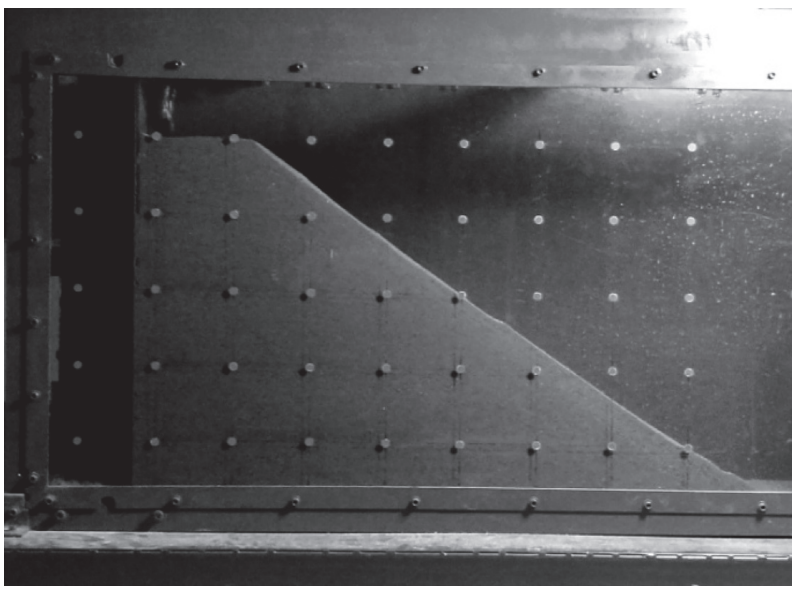

Figure 11: The test box.

6.1. Test Equipment and Arrangements. The model test uses a laboratory-made model box with a size of $1200 \mathrm{~mm}$ (length) $\times 425 \mathrm{~mm}$ (width) $\times 700 \mathrm{~mm}$ (height), as shown in Figure 11, for the active earth pressure test of land slideshaped finite width sand [28, 29]. In order to ensure the accuracy and stability of the active earth pressure measurement, customized resistance-strain micro-earth pressure gauges are used with arranging 8 measuring points along the vertical centerline area of the steel movable retaining wall. The earth pressure gauges are embedded in the pregrooved movable baffle, and static resistance strain gauges are used to measure the values.

The purpose of the model test is mainly to test the active earth pressure distribution of the finite-width grading soil after the rigid retaining wall under the translational displacement. Four tests were carried out using the cohesionless sand soil sample. The specific model parameters are shown in Table 2. The mechanical parameters of the sand in this test are as follows: internal friction angle $\varphi=39.6^{\circ}$, gravity
TABle 2: List of tests.

\begin{tabular}{lccc}
\hline Test number & Soil height $(\mathrm{m})$ & Slope top width $(\mathrm{m})$ & Aspect ratio \\
\hline I & 0.500 & 0.050 & 0.10 \\
II & 0.500 & 0.100 & 0.20 \\
III & 0.500 & 0.150 & 0.30 \\
IV & 0.500 & 0.200 & 0.40 \\
\hline
\end{tabular}

$\gamma=16.1 \mathrm{kN} / \mathrm{m}^{3}$, water content $w=5 \%$, slope bottom angle $\beta=33.7^{\circ}$, and the outer friction angle is $\delta=2 / 3 \varphi$.

6.2. Test Results and Analysis. After the test, the active earth pressure distributions of three groups of sands with different aspect ratios were compared with the theoretical calculation results, as shown in Figure 12.

It can be seen from Figure 12 that the active earth pressure distribution pattern calculated by the method of this paper is similar to the soil pressure distribution curve of 


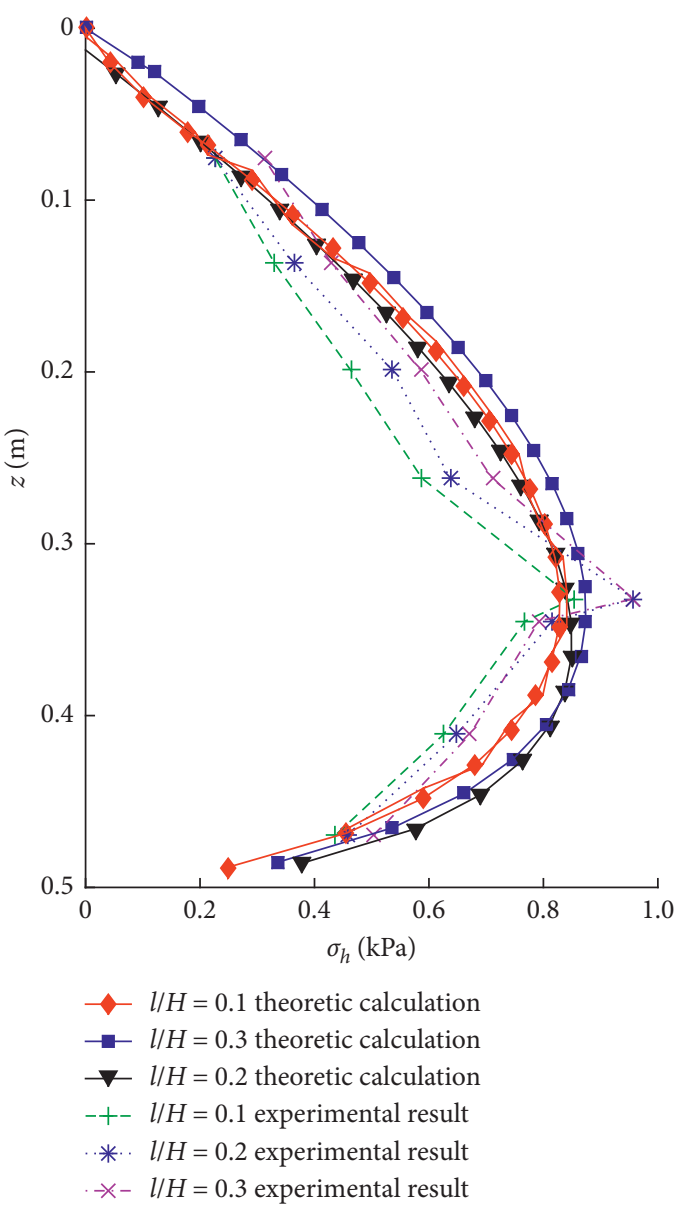

FIGURE 12: Distribution of earth pressure.

the laboratory model test, and the practice is consistent. The drum shape is present in the lower part of the wall body, mainly due to the soil arching effect. The decrease of the earth pressure intensity in the middle and lower part of the wall is also caused by the soil arching. The finite soil pressure obtained by the model test is close to the calculated value of the theoretical method in this paper, but there are still some gaps, indicating that the accuracy and parameters of the test needed to be further improved in the later research.

\section{Conclusion}

(1) With summarizing the engineering characteristics of the sloping finite-width soil such as the retaining wall for the embankment or adjacent foundation pits, the limit rupture angle in soil sliding failure under the translational mode of the rigid retaining wall is obtained by the optimization algorithm according to the rigid-body equilibrium coulomb theory.

(2) Based on the plane sliding failure mode, the sloping finite-width soil is divided into three zones. Through introducing soil arch theory and considering the horizontal shear stress between horizontal microlayers, the horizontal microstratification analysis method is modified and the calculation formula for obtaining the resultant active earth pressure on rigid retaining wall with sloping finite-width soil, the earth pressure distribution, and the height of the resultant force point is obtained.

(3) The analysis has indicated that, as the aspect ratio increases, the limit rupture angle of finite soils decreases and the active resultant force gradually enlarges to approach coulomb's value of semi-infinite soil. The distribution curve of active earth pressure horizontal component was nonlinear drum shaped considering the horizontal arch shear stress between the soil arch and the soil layer, and it is detected that the position of the finite earth pressure combined force was obviously higher than the Coulomb theoretical value. As the outer friction angle of the wall increases, the active earth pressure resultant force value decreases while the distance between the resultant force points and the bottom of the wall increases, and as the aspect ratio $l / H$ increases, the position of the resultant force points increases and tends to a certain value.

(4) The laboratory model test results have demonstrated that the active earth pressure distribution pattern calculated by the improved differential layer method is close to the test soil pressure distribution curve. However, the model test in this paper only changes the aspect ratio of soil, without considering other factors such as slope angle, wall height, and friction condition, which is needed to further research in the follow-up work.

\section{Data Availability}

The data and figures used to support the findings of this study are included within the article.

\section{Conflicts of Interest}

The authors declare that they have no conflicts of interest.

\section{Acknowledgments}

The authors' research was supported by the National Natural Science Foundation of China (No. 51708209), Hunan Natural Science Foundation (2017JJ2110), and the Innovation Project of Hunan Undergraduate Students (No. S201910543048).

\section{References}

[1] N. S. Frydman and I. Keissar, "Earth pressure on retaining walls near rock faces," Journal of Geotechnical Engineering, ASCE, vol. 113, no. 6, pp. 586-599, 1987.

[2] W. A. Take and A. J. Valsangkar, "Earth pressures on unyielding retaining walls of narrow backfill width," Canadian Geotechnical Journal, vol. 38, no. 6, pp. 1220-1230, 2001.

[3] K. H. Yang, K. T. Kniss, and S. G. "Wright, "Finite element analyses for centrifuge modelling of narrow MSE walls," in Proceedings of the the 1st Pan American Geosynthetics 
Conference \& Exihibition, pp. 1623-1630, Cancun, Mexico, March 2008.

[4] F. Chen, Y. Lin, and D. Li, "Solution to active earth pressure of narrow cohesionless backfill against rigid retaining walls under translation mode," Soils and Foundations, vol. 59, no. 1, pp. 151-161, 2019.

[5] F. Q. Chen, J. T. Yang, and Y. J. Lin, "Active earth pressure of narrow granular backfill against rigid retaining wall near rock face under translation mode," International Journal of Geomechanics, vol. 19, no. 12, 2019.

[6] Z. Y. Liu, "Active earth pressure calculation of rigid retaining walls with limited granular backfill space," China Journal of Highway Transport, vol. 31, no. 2, pp. 154-164, 2018.

[7] Y. X. Jie, "Analyses on finite earth pressure and slope safely factors," Journal of Tsinghua University (Science and Technology), vol. 59, no. 8, pp. 619-627, 2019.

[8] M. X. Xie, J. J. Zhen, and W. Z. Cao, "Study of active earth pressure against embankment retaining wall of limited backfill," Journal of Huazhong University of Science and Technology (Natural Science Edition), vol. 47, no. 2, pp. 1-6, 2019.

[9] X. Liu, "Active earth pressure for limited soils in grading condition by numerical analysis method," Southwest Highway, no. 2, pp. 44-46, 2013, in Chinese.

[10] X. R. Xie, K. N. Zhang, H. W. Xu et al., "Active earth pressure for limited soils by upper limit method," West-china Exploration Engineering, no. 9, pp. 22-23, 2005, in Chinese.

[11] T. Fang, H. L. Wang, R. R. Yang, and et al., "Active earth pressure calculation of limited soil in grading conditions," Journal of East China Jiaotong University, vol. 33, no. 4, pp. 50-55, 2016.

[12] Y. S. Fang and I. Ishibashi, "Static earth pressures with various wall movements," Journal of Geotechnical Engineering, vol. 112, no. 3, pp. 317-333, 1986.

[13] C.-C. Fan and Y.-S. Fang, "Numerical solution of active earth pressures on rigid retaining walls built near rock faces," Computers and Geotechnics, vol. 37, no. 7-8, pp. 1023-1029, 2010.

[14] M. H. Khosravi, T. Pipatpongsa, and J. Takemura, "Experimental analysis of earth pressure against rigid retaining walls under translation mode," Géotechnique, vol. 63, no. 12, pp. 1020-1028, 2013.

[15] H. W. Ying, D. Huang, and X. Y. Xie, "Study of active earth pressure on retaining all subject to translation mode considering lateral pressure on adjacent existing basement exterior wall," Chinese Journal of Rock Mechanics and Engineering, vol. 30, no. 1, pp. 2970-2978, 2011, in Chinese.

[16] Y.-Z. Wang, "Distribution of earth pressure on a retaining wall," Géotechnique, vol. 50, no. 1, pp. 83-88, 2000.

[17] M. H. Yang, L. C. Wang, and M. H. Zhao, "Calculation of active earth pressure for finite soils based on the soil arching theory," Building Structures, vol. 43, no. 2, pp. 71-75, 2013.

[18] S. S. Nadukuru and R. L. Michalowski, "Arching in distribution of active load on retaining walls," Journal of Geotechnical and Geoenvironmental Engineering, vol. 138, no. 5, pp. 575-584, 2012.

[19] R. L. Handy, "The arch in soil arching," Journal of Geotechnical Engineering, vol. 111, no. 3, pp. 302-318, 1985.

[20] Z. Y. Liu, J. Chen, and D. Y. Li, "Calculation of active earth pressure against rigid retaining wall considering shear stress," Rock and Soil Mechanics, vol. 37, no. 9, pp. 2443-2450, 2016, in Chinese.

[21] L. Chen, Y. X. Zhang, and K. X. Ran, "Method for calculating active earth pressure considering shear stress," Rock and Soil Mechanics, vol. 32, no. Supp.2, pp. 219-223, 2009, in Chinese.
[22] C. F. Wu, Z. J. Zhang, and S. H. Liu, "Calculation method for lateral earth pressure on parallel retaining wall with clayey back fill considering soil arching effect," China Journal of Highway and Transport, vol. 27, no. 4, pp. 31-37, 2014, in Chinese.

[23] J. Wang, T. D. Xia, P. F. He et al., "Analysis of active earth pressure on rigid retaining walls considering soil arching," Rock and Soil Mechanics, vol. 35, no. 7, pp. 1914-1920, 2014, in Chinese.

[24] J. M. Zhu and Q. Zhao, "Unified solution to active earth pressure and passive earth pressure on retaining wall considering soil arching effects," Rock and Soil Mechanics, vol. 35, no. 9, pp. 2501-2505, 2014, in Chinese.

[25] M. G. Li, J. J. Chen, and J. H. Wang, "Arching effect on lateral pressure of confined granular material: numerical and theoretical analysis," Gramular Matter, vol. 19, no. 2, pp. 1-11, 2017.

[26] H. W. Ying and Q. P. Cai, "Distribution of active earth pressure against flexible retaining walls with drum deformation," Chinese Journal of Geotechnical Engineering, vol. 30, no. 12, pp. 1805-1810, 2008.

[27] K. H. Paik and R. Salgado, "Estimation of active earth pressure against rigid retaining walls considering arching effects," Géotechnique, vol. 53, no. 7, pp. 643-653, 2003.

[28] M. H. Yang, X. B. Dai, M. H. Zhao et al., "Experimental study on active earth pressure of cohesionless soil with limited width behind retaining wall," Chinese Journal of Geotechnical Engineering, vol. 38, no. 1, pp. 131-137, 2016, in Chinese.

[29] W. D. Hu, X. N. Zhu, and X. Y. Zhou, "Experimental study on passive earth pressures of cohesionless soils with limited width against cantilever piles flexible retaining walls," Chinese Journal of Rock Mechanics and Engineering, vol. 38, no. supp.2, pp. 3748-3757, 2019, in Chinese. 